\title{
Development of simplified WQIs for assessment of spatial and temporal variations of surface water quality in upper Damodar river basin, eastern India
}

\author{
Ravindra Kumar Verma ${ }^{1} \cdot$ Shankar Murthy ${ }^{2} \cdot$ Rajani Kant Tiwary $^{3} \cdot$ Sangeeta Verma $^{4}$
}

Received: 25 July 2017 / Accepted: 3 January 2019 / Published online: 22 January 2019

(C) The Author(s) 2019

\begin{abstract}
In this study, four surface water quality datasets of upper Damodar river basin (DRB) covering three seasons; pre-monsoon, monsoon, post-monsoon and annual, for years 2007-2010 were generated by analyzing 280 grab water samples. Each dataset consist of water quality constituents of 35 monitoring stations and sample of each station was evaluated by 17 critical parameters (total 4760 observations). Furthermore, each dataset was treated using six water quality indices (WQIs): four developed simplified indices $\left(\mathrm{WQI}_{\mathrm{m}}, \mathrm{WQI}_{\mathrm{min}}, \mathrm{WQI}_{\mathrm{DO}}\right.$, and $\mathrm{WQI}_{\mathrm{pca}}$ ) and two existing extended indices $\left(\mathrm{WQI}_{\mathrm{obj}}\right.$ and $\mathrm{WQI}_{\mathrm{sub}}$ ), to assess spatiotemporal variations and suitability for human use and aquatic life. Results revealed that developed indices show on an average similar spatiotemporal variations as compared to $\mathrm{WQI}_{\mathrm{obj}}$ at a lower analytical cost at most of sampling sites comes under good to medium categories of water quality. Geographical information system (GIS) technique was also used for generation of temporal pollution potential maps of DRB. Consequently, this study also presents the necessity and usefulness of developed indices over extended indices especially for the developing countries, because the cost of monitoring and expenses associated with the implementation is less compared to extended methods and generated maps may also facilitate the decision-making processes under various scenarios considering spatial and temporal variability in DRB.
\end{abstract}

Keywords Damodar river basin $\cdot$ Water quality index $\cdot$ Geographical information system

\section{Introduction}

Assessment of water quality is important because clean water is necessary for human use and the integrity of aquatic ecosystem. It is usually monitored through conventional method, which involves in situ measurements of physical, chemical, biological, microbiological, and radiological

Ravindra Kumar Verma

ravindraverma.nitie@gmail.com

$1 \quad$ National Mission on Himalayan Studies - Project Management Unit (NMHS-PMU), GBPNIHESD, Kosi, Katarmal, Almora, Uttarakhand 263643, India

2 Environmental Engineering and Management Group, National Institute of Industrial Engineering (NITIE), Vihar Lake, Mumbai 400087, India

3 Water Environment Division, Central Institute of Mining and Fuel Research (CIMFR), Barwa-Road, Dhanbad, Jharkhand 826015, India

4 National Institute of Hydrology (NIH), Roorkee, Uttarakhand 247667, India parameters and/or the collection of water samples for laboratory analysis and then comparing with the existing guidelines and standards for designated uses viz drinking, bathing, irrigation provided by national and international agencies. But, guidelines for the protection of aquatic life are more difficult to set, largely because aquatic ecosystems vary enormously in their composition both spatially and temporally, and also because ecosystem boundaries rarely coincide with territorial ones. Therefore, scientific community are focusing on the spatiotemporal variations of water quality constituents and impacts of geographical factors and variations in human activities.

The conventional method is readily understood and well accepted only among water professionals, as it involves multiple parameters (Cude 2001). However, even by using multiple parameters, it is not possible to accurately estimate the overall water quality. To accomplish this, water quality index (WQI) is an alternative method that summarizes a large volume of information from multiple variables into a single variable ranging from 0 to 100 , which is easy to understand and interpret about spatiotemporal variations of 
water quality as well as possible uses of a given water body (Cude 2001; Kannel et al. 2007a, b).

WQI gives acceptable information at certain times and locations, if it is computed using limited number of critical water quality parameters based on regional watershed characteristics and suitable aggregation function. Thus, firstly, a set of critical parameters need to be chosen, which together reflect the overall water quality for designed uses (Ongley 1998). Otherwise, it may also become unwieldy if each and every possible constituent is included in the index (Akkoyounlu and Akiner 2012). Secondly, aggregation function, whereby multidimensional subindex information is reduced to overall a single value as index. However, aggregation technique exhibits both substantive and structural shortcomings such as ambiguity (overestimation), eclipsing (underestimation), rigidity, and sensitivity (Singh et al. 2008; Swamee and Tyagi 2007). Ambiguity problem exists where the aggregate index is too high and crosses a critical level. Eclipsing happens when the effect of a very high (perhaps catastrophic) subindex value is lost in the aggregated index because of a low weighting factor. Rigidity problem exists when additional variables are included in the index to address specific water quality concerns. Besides these, aggregation function also possesses a high sensitivity to the changes in subindices of the selected water pollutant variables (Kumar and Alappat 2004; Sutadian et al. 2016).

Alternatively, other researchers have also used multivariate statistical techniques such as correlation analysis (CA), principal component analysis (PCA), factor analysis (FA), and Fuzzy analysis method to reduce the dimensionality of the physicochemical-biological parameters (Debels et al. 2005; Hanh et al. 2011; Liou et al. 2004; Koçer and Sevgili 2014). Furthermore, these techniques are often used to modify WQI with a minimum number of parameters for assessment of water quality of any water bodies.

Keeping the fact of minimum analytical cost involved and selection of appropriate aggregation functions for prediction of water quality in mind, the objectives of the present study are: (1) to develop simplified WQIs and also explore usefulness of these over extended indices, (2) to assess the spatial and temporal variations of water quality using both simplified and extended WQIs (3) to classify the river water quality and (4) to identify the water quality index that is effective and quick assessable at low cost.

\section{Earlier WQI}

The use of WQI was initially proposed by Horton (1965). Since 1965, a number of WQIs have been developed by different researchers to evaluate water quality based on different aggregation functions. Most frequently used functions are: weighted averaging methods (Ball and Church 1980;
Brown et al. 1970; House and Ellis 1987; Jonnalagadda and Mhere 2001; Pesce and Wunderlin 2000; Ross 1977; Štambuk-Giljanovic 1999), weighted geometric means (Dinius 1987), minimum operators (Smith 1990), and hybrid methods (Dojlido et al. 1994; Liou et al. 2004; Swamee and Tyagi 2000). However, these developed indices have one or the other shortcomings such as ambiguity, eclipsing, and rigidity, due to faulty selection of aggregation function. Faulty aggregation function might artificially reduce the value of the aggregate index, such that it does not accurately reflect the true water quality. Therefore, search for a perfect one is still a challenge.

Two forms of aggregation functions: (1) arithmetic or additive and (2) geometric or multiplicative are commonly used, which suffer from both eclipsing and ambiguous effects (Cude 2001; Liou et al. 2004; Ott 1978; Smith 1990). Smith (1990) and Ott (1978) claimed that the problem of eclipsing might occur due to fewer representatives at the lower end of the quality scale when the additive form is applied in aggregation.

Brown et al. (1970) represented National Sanitation Foundation's Water Quality Index (NSF-WQI) used unweighted arithmetic mean function as depicted in Eq. 1. This function shows ambiguous, eclipsing, and little flexibility.

$\mathrm{WQI}_{\mathrm{uwa}}=\sum_{i=1}^{1} P_{i}$

Later, Prasad and Bose (2001) and Sarkar and Abbasi (2006) used weighted arithmetic mean aggregation function, which is expressed as Eq. 2. This function shows ambiguity free but still has small eclipsing with large number of variables.

$\mathrm{WQI}_{\mathrm{wa}}=\sum_{i=1}^{n} P_{i} C_{i}$

Pesce and Wunderlin (2000) and Debels et al. (2005) used weighted average concentration function in their studies, which is expressed as Eq. 3. This function exhibits low sensitivity to changes in subindices for large number of variables

$\mathrm{WQI}_{\mathrm{wac}}=k \frac{\sum_{i=1}^{n} P_{i} C_{i}}{\sum_{i=1}^{n} P_{i}}$

where $C_{i}$ is the normalized subindex values; $P_{i}$ is the weighting factor that changes between 0 and 1 (according to relative importance for aquatic life/human use); $i$ is the parameter, which ranges from 1 to $n ; k$ is the subjective constant and $n$ is the total number of parameters. 
The other multiplicative formulation, which is shown in Eqs. (4) and (5), was suggested by researchers (e.g., Almeida et al. 2012; Bhargava 1985; Brown et al. 1973; Walski and Parker 1974). It may be ambiguity free but exhibits eclipsing at low weights and increasing scale indices.

$\mathrm{WQI}=\prod_{i=1}^{N} S_{i}^{w_{i}}$

$\mathrm{WQI}=\prod_{i=1}^{N} S_{i}^{1 / n}$

where WQI-is the aggregated index, $n$-is the number of subindices, $w_{i}-$ is the $i$ th weight and $S_{i}$-is the $i$ th subindex. The weights $\left(w_{i}\right)$ indicate the relative importance of $S_{i}$. When the weights in Eq. (4) are equal, then the equation takes the form presented in Eq. (5).

Smith (1990) used the minimum operator as an aggregation function:

$\mathrm{WQI}=\min \left(s_{1}, s_{2}, s_{3}, s_{4}, \ldots \ldots \ldots s_{N}\right)$

Equation 6 does not have an eclipsing problem when the index has the minimum subindex value; it fails to give a composite picture of water quality.

On the other hand, some researchers have also used "normalization" technique in earlier aggregation functions. Normalized values of different water quality parameters are given in Table 1, which are based on European Standards (EU 1975) as well as expert opinion and variety of sources from the literature (Akkoyounlu and Akiner 2012; Cude 2001; Ott 1978; Pesce and Wunderlin 2000). Normalized value does not show rigidity problems, because considering values are suggested by expert opinion.

Later, Liou et al. (2004) suggested that a combined form of both additive and multiplicative is better approach than a single one to produce the final index score which could eliminate ambiguity caused due to smaller weightings. A major drawback in the multiplicative form is that if any variable exhibits a low score value, then the overall index will exhibit poor environmental quality. Singh et al. (2008) conducted a comparative study of 18 different types of aggregation functions and finally concluded that weighted arithmetic mean function is true linear, least ambiguous, and eclipsing free in estimating pollution or WQI for the river Ganga. Some other aggregation function might have shown superiority. Thus, they also suggested that the best idea is to use a mix aggregation function by categorization of measured water quality parameters into groups. Furthermore, WQI was improved in the form of a weighted additive model, unweighted version, and weighted average concentration function. Pesce and Wunderlin (2000) categorized WQI ${ }_{\mathrm{wac}}$ into two types: (1) subjective WQI (WQI ${ }_{\text {sub }}$ ) and (2) objective WQI (WQI ${ }_{\text {obj }}$ ) based on different value of $k$, given in Eq. 3. The WQI ${ }_{\text {sub }}$ represents the visual impression of the contamination level of a monitoring station. It takes one of the $k$ values according to the river condition. The values of $k$ are: $1=$ water without apparent contamination (clear or with natural suspended solids); $0.75=$ light contaminated water (apparently), indicated by light non-natural color, foam, light turbidity due to manmade pollutants reasons; $0.50=$ contaminated water (apparently), indicated by non-natural color, light to moderate odor, high turbidity (no natural), suspended organic solids, etc.; $0.25=$ highly contaminated water (apparently), indicated by blackish color, hard odor, visible fermentation, etc., whereas $\mathrm{WQI}_{\text {obj }}$ can be calculated using Eq. 3 but with $k=1$ in any case.

In the last decade, researchers have also suggested simplified WQIs approaches and use of limited water quality constituents for water quality assessment especially for the developing countries. The reason behind this approach is to minimize the cost and quick assessment of overall water quality and proved an advantage over conventional and extended WQI methods. Pesce and Wunderlin (2000) used three parameters (EC, turbidity, and DO), while Kannel et al. (2007a, b) used five parameters (EC, Tw, DO, pH, and TSS) for computing $\mathrm{WQI}_{\min }$ to determine overall water quality of river Suquía (Argentina) and Bagmati (Nepal), respectively. Simoes et al. (2008) considered only three parameters (turbidity, total phosphorus, and DO) for computing $\mathrm{WQI}_{\text {moc }}$ to assess the effect of fish farming activities in Macuco and Queixada rivers in Madio Paranapanema watershed in Brazil. These indices usefully served as a simple tool to monitor spatial and temporal trends of water quality in place of a conventional index, unless drastic changes in natural or anthropogenic activities would lead to completely different contamination load compositions.

\section{Study area}

This study was conducted in upper and middle regions of Damodar river basin (DRB). The basin is mainly drained by Damodar river which provides drinking water sustenance to millions of people in and around the river. It is a small rain-fed perennial river originating from the Khamerpet hill (elevation; $1068 \mathrm{~m}$ ). The river Damodar flows for $541 \mathrm{~km}$ of which $240 \mathrm{~km}$ stretch is in Jharkhand and the rest is in West Bengal in eastern India and finally meets the Bay of Bengal.

The basin area is approximately $23,170 \mathrm{~km}^{2}$, which lies between $22^{\circ} 15^{\prime} \mathrm{N}$ to $24^{\circ} 30^{\prime} \mathrm{N}$ latitude and $84^{\circ} 30^{\prime} \mathrm{E}$ to $88^{\circ} 15^{\prime} \mathrm{E}$ longitude. It has number of tributaries and subtributaries, such as Barakar, Konar, Garga nalla, Jamunia, Khudia, Katri, Noonia, and Tamna nalla. It also has five reservoirs; two are located on Damodar river at Tenughat and Panchet, two 


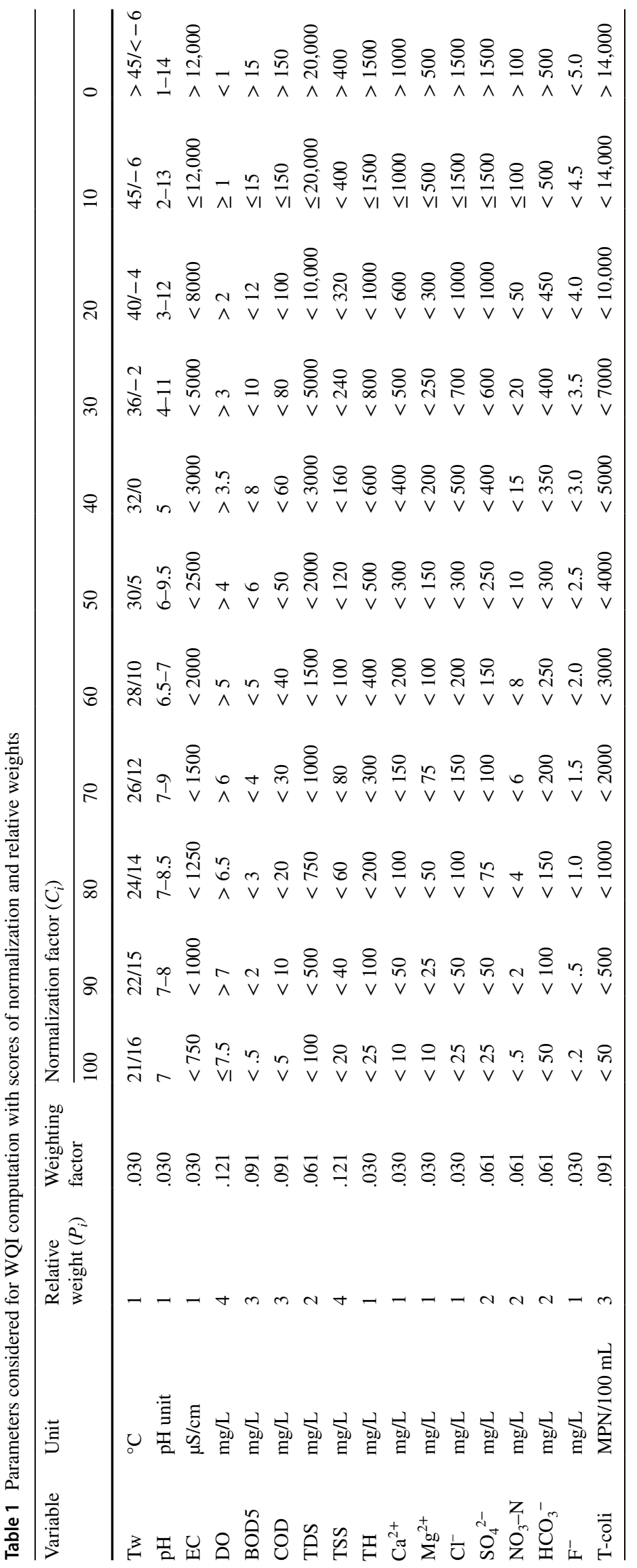




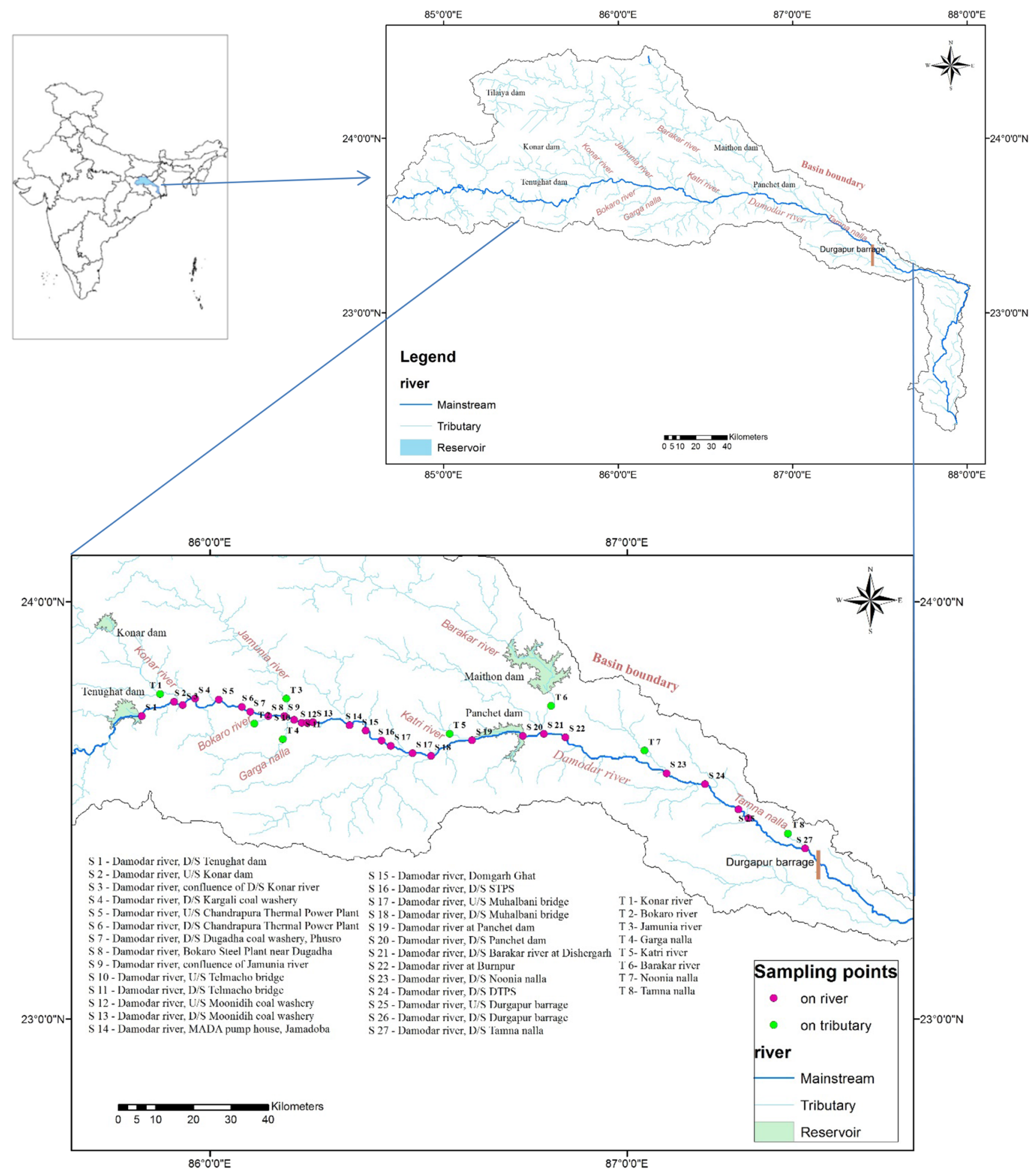

Fig. 1 Map showing location of study area and sampling points

on Baraker river at Tilaiya and Maithon, and one on Konar river (Fig. 1).

The basin is also rich in deposits of coal (approximately $46 \%$ of the Indian coal reserves), minerals, all of which are heavily mined. Besides mining, 182 non-coal mines, 78 urban centers, 82 industrial centers, 4 coal-fired thermal power plants, 2 steel plants unplanned growth of urban and other settlements, heavy encroachments along both banks 
of the river cause water pollution (Tiwary 1990; Verma et al. 2013). These anthropogenic activities such as damming, industrialization, urbanization, and encroachment have affected the river system including water quality and quantity as well as aquatic life.

In addition, the major sources of water pollution are discharge of effluents generated due to various industries that have mushroomed on its riverbanks. Majority of them are government-owned coke oven plants, coal washeries, iron and steel plants, cement plants, and thermal power plants. Their effluent discharge brings excessive fly ash, poisonous metals, as well as coal dust (Tiwary 2004), which go directly into the river. Mining and its associated mineral processing activities withdraw a lot of water and also impact on the hydrological regime of the river and often affect the water quality. Runoff from dumps and drainage from mining surface carry substantial amounts of suspended solids or sediment suspension.

The basin experiences tropical climate; summer is usually very hot and dry with average temperature of $30^{\circ} \mathrm{C}$ and in May-July month, temperature could reach up to $48^{\circ} \mathrm{C}$. Winter is cold; temperature could be as low as $2{ }^{\circ} \mathrm{C}$. The mean annual precipitation ranges from 765 to $1850 \mathrm{~mm}$ with an average value of $1250 \mathrm{~mm} ; 80 \%$ of the rainfall occurs during monsoon season between June and September month.

\section{Methodology}

\section{Sampling strategy and analytical procedures}

A total of 35 sampling sites were selected: 27 sites (S1-S27) along river Damodar and 8 sites (T1-T8) from its eight tributaries between stretches of about $132 \mathrm{~km}$ from downstream of Tenughat dam to downstream of Tamna nalla (Fig. 1). Total 280 grab water samples were collected for periods of 2007-2010 during pre-monsoon (April-May 2007, 2008, 2009, 2010), post-monsoon (November-December 2007, 2008, 2009) and once in monsoon (August-September 2008) season.

Furthermore, samples were analyzed as per Standard Methods (APHA 2005) and generated four datasets of 17 critical water quality parameters such as water temperature (Tw), $\mathrm{pH}$, electric conductivity (EC), total dissolved solids (TDS), total suspended solids (TSS), dissolved oxygen (DO), 5-day biochemical oxygen demand $\left(\mathrm{BOD}_{5}\right)$, total hardness $(\mathrm{TH})$, chemical oxygen demand (COD), nitrate-nitrogen $\left(\mathrm{NO}_{3}{ }^{-}-\mathrm{N}\right)$, sulfate ion $\left(\mathrm{SO}_{4}{ }^{2-}\right)$, calcium ion $\left(\mathrm{Ca}^{2+}\right)$, magnesium ion $\left(\mathrm{Mg}^{2+}\right)$, chloride ion $\left(\mathrm{Cl}^{-}\right)$, fluorides ion $\left(\mathrm{F}^{-}\right)$, bicarbonate ion $\left(\mathrm{HCO}_{3}{ }^{-}\right)$, and total coliforms (T-coli). Tw was recorded on spot. Rest other parameters were measured in the water laboratory of the CIMFR, Dhanbad; $\mathrm{pH}$ values were measured using Orion ATI ion analyzer (EA
960); EC by conductivity meter (Model No. C831 multiparameter analyzer); $\mathrm{BOD}_{5}$ and $\mathrm{DO}$ were determined by titration method. TSS and TDS were separated by filtering the samples through $.42 \mathrm{~mm}$ Whatman filter paper and determined according to standard methods (APHA 2005). Anions $\left(\mathrm{Cl}^{-}, \mathrm{F}^{-}, \mathrm{SO}_{4}{ }^{2-}, \mathrm{NO}_{3}{ }^{-}-\mathrm{N}\right.$, and $\left.\mathrm{HCO}_{3}{ }^{-}\right)$were determined by ion chromatograph (882 compact ion-plus). T-coli (MPN/100 mL) were assayed according to the multiple tube fermentation method, taking the more probable number.

\section{WQI computation and development}

Normally, WQI computation requires four steps: (1) the raw analytical results for the optimum set of water quality parameters, having different units of measurements, (2) normalize all these parameters into $0-100$ scale, where 100 represents the maximum quality, (3) apply a weighting factor in accordance with the importance of the parameters in determining water quality, and (4) combine these two normalized and weighting factors using suitable aggregation function/s into overall index.

In order to avoid rigidity problem, significance ratings, weight assign values, and normalization factor as given in Table 1 were used to compute both extended as well as the proposed simplified indices. Extended indices: $\mathrm{WQI}_{\mathrm{obj}}$ and $\mathrm{WQI}_{\text {sub }}$ (considering all 17 parameters), were calculated using Eq. (3), while $\mathrm{WQI}_{\mathrm{obj}}$ was calculated with $k=1$ in all the cases, because all the sites along Damodar river appeared clear during the time of sampling.

In addition, to avoid possible misinterpretation of results, all discussed WQIs were applied on all four datasets to classify river water into five categories: (1) 0-25, (2) 26-50, (3) 51-70, (4) 71-90, and (5) 91-100 as very bad, bad, medium, good, and excellent water quality, respectively. Furthermore, Geographical information system (GIS) technique was also used for generating spatiotemporal pollution potential maps of DRB on software package ArcGIS 9.1 Desktop.

\section{Developing WQI using minimum number of parameters}

Kannel et al. (2007a, b) developed an index "WQI ${ }_{\min }$," which was computed based on five parameters (EC, Tw, DO, $\mathrm{pH}$, and TSS) using Eq. 7. This is one way to minimize associated analytical cost and also important in view of drinking and aquatic life.

$\mathrm{WQI}_{\min }=\frac{\sum_{i=1}^{5} P_{i} * C_{i}}{5}$

DO is probably the most important parameter in any water body. It also influences other parameters. Recognizing 
this fact, the empirical relationships between $\mathrm{WQI}_{\mathrm{obj}}$ and DO have been developed as "WQI DO" (Debels et al. 2005; Kannel et al. 2007a, b).

By using similar concept, two new indices: (1) minimal WQI (WQI ${ }_{m}$ ) and (2) $\mathrm{WQI}_{\mathrm{DO}}$, were developed considering minimum number of parameters. The $\mathrm{WQI}_{\mathrm{m}}$ was generated by a regression analysis between the results of $\mathrm{WQI}_{\mathrm{obj}}$ and WQI ${ }_{\min }(\alpha$ and $\beta$ are regression constants) as shown in Eq. (8):

$\mathrm{WQI}_{\mathrm{m}}=\alpha \mathrm{WQI}_{\min }+\beta$

In case of $\mathrm{WQI}_{\mathrm{DO}}$, single parameter $\mathrm{DO}$ was used. The relationships between $\mathrm{WQI}_{\mathrm{obj}}$ and DO were also derived using linear regression model as shown in Eq. (9):

$\mathrm{WQI}_{\mathrm{DO}}=\alpha \mathrm{DO}+\beta$

\section{Development of simplified WQI based on PCA}

Another simplified index "WQI pca" was also developed by coupling two methodologies: mix aggregation function (arithmetic and multiplicative) and PCA. PCA is a widely accepted method to categorize parameters used in the WQI calculations, which are having common features and are responsible for most of the variation observed in measured data (Debels et al. 2005). This index would optimize the eclipsing and sensitivity problems in conventional methodologies through the parameter categorization.

Considering the additional fact that weights and normalization factor of different water quality constituents were used (Table 1) in the calculation of $\mathrm{WQI}_{\mathrm{pca}}$ which would also reduce rigidity problem.

\section{Statistical analysis}

Statistical analysis involves linear regression model, oneway analysis of variance (ANOVA) and PCA. A linear regression model was used to determine empirical relationships among computed WQIs and DO. ANOVA was conducted to examine the statistical significance of differences in the means of WQIs computed during different seasons at $P<.005$. All the statistical processing was performed using SPSS 16 software for windows.

\section{Results and discussion}

\section{Development of $W_{\mathrm{WQI}}$ and $\mathrm{WQI}_{\mathrm{DO}}$}

Two new simplified indices: $\mathrm{WQI}_{\mathrm{m}}$ and $\mathrm{WQI}_{\mathrm{DO}}$ were generated by regression analysis between the values of $\mathrm{WQI}_{\mathrm{obj}}$ (called WQI $\mathrm{m}_{\mathrm{m}}$ hereafter) and $\mathrm{WQI} \mathrm{I}_{\min }$ and $\mathrm{DO}$, respectively.

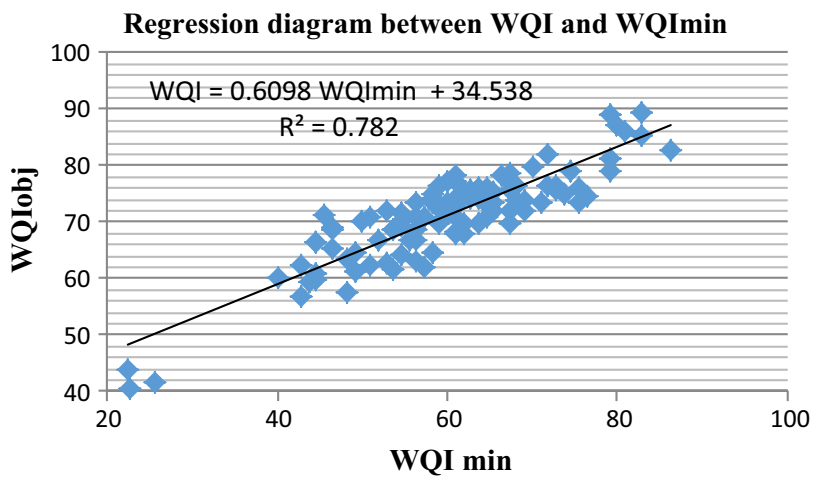

Fig. 2 Regression diagram between $\mathrm{WQI}_{\mathrm{obj}}$ and $\mathrm{WQI}_{\min }$ values obtained from 35 sampling sites in DRB

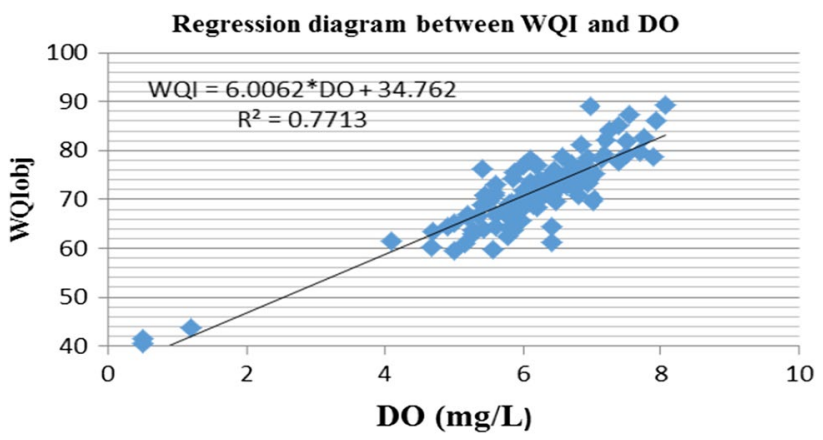

Fig. 3 Regression diagram between $\mathrm{WQI}_{\mathrm{obj}}$ and $\mathrm{DO}$ values obtained from 35 sampling sites in DRB

First, linear relationship was observed between $\mathrm{WQI}_{\mathrm{obj}}$ and $\mathrm{WQI}_{\text {min }}$, which is given as Eq. 10 and shown in Fig. 2. Second, linear relationship between $\mathrm{WQI}_{\mathrm{obj}}$ (hereafter called $\mathrm{WQI}_{\mathrm{DO}}$ ) and DO was observed as Eq. (11) and shown in Fig. 3. Figures 2 and 3 reveal that there exists a high correlation for the mean seasonal value (105 numbers). Regression fits well with the determination coefficient $\left(R^{2}=.782\right.$ and .771 ), which shows reliability.

$\mathrm{WQI}_{\mathrm{m}}=0.6098 * \mathrm{WQI}_{\min }+34.538\left(R^{2}=0.782, P<0.000\right)$

$\mathrm{WQI}_{\mathrm{DO}}=6.0062 * \mathrm{DO}+34.762\left(R^{2}=0.7713, P<0.000\right)$

\section{PCA analysis and development of simplified index "WQI pca"}

To distinguish temporal differences and development of

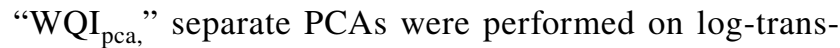
formed datasets of all four datasets: pre-monsoon, monsoon, post-monsoon and annual. In the analysis, raw data were 
transformed into new uncorrelated variables, called principal components (PCs).

Due to the paucity of space, the result of only annual dataset is presented here. From the annual dataset, five PCs were extracted, together explaining $79 \%$ of the variance of information contained in the original data (Table 2). PC1 accounted for $33.79 \%$ of total variance, indicating positive loading on $\mathrm{BOD}_{5}, \mathrm{COD}, \mathrm{SO}_{4}{ }^{2-}, \mathrm{NO}_{3}{ }^{-}-\mathrm{N}$ and negative

Table 2 The component matrix, eigenvalues, and cumulative extracted PCs

\begin{tabular}{|c|c|c|c|c|c|}
\hline & PC1 & $\mathrm{PC} 2$ & PC3 & PC4 & PC5 \\
\hline \multicolumn{6}{|l|}{ Loading of variables } \\
\hline Tw & .029 & .058 & .283 & -.058 & -.069 \\
\hline $\mathrm{pH}$ & .067 & .101 & -.052 & .030 & .991 \\
\hline $\mathrm{EC}$ & .005 & .118 & .320 & -.018 & .191 \\
\hline DO & -.581 & -.340 & -.317 & -.097 & -.048 \\
\hline $\mathrm{BOD}_{5}$ & .562 & .426 & .104 & .097 & .033 \\
\hline COD & .685 & .332 & .270 & -.044 & .073 \\
\hline TDS & .268 & .162 & .642 & .086 & .049 \\
\hline TSS & .512 & -.420 & .657 & .197 & -.065 \\
\hline $\mathrm{TH}$ & .202 & .648 & .193 & -.009 & -.042 \\
\hline $\mathrm{Ca}^{2+}$ & .313 & .053 & .093 & -.041 & .004 \\
\hline $\mathrm{Mg}^{2+}$ & .260 & .283 & .272 & -.186 & .034 \\
\hline $\mathrm{SO}_{4}{ }^{2-}$ & .725 & .146 & .129 & .267 & .121 \\
\hline $\mathrm{NO}_{3}{ }^{-}-\mathrm{N}$ & .955 & .030 & -.089 & .018 & .019 \\
\hline $\mathrm{Cl}^{-}$ & .323 & .335 & .210 & .276 & .164 \\
\hline $\mathrm{F}^{-}$ & .154 & .160 & .104 & .002 & .123 \\
\hline $\mathrm{HCO}_{3}^{-}$ & .097 & .321 & -.038 & -.162 & .058 \\
\hline T-coli & .145 & .192 & -.436 & .797 & .087 \\
\hline Eigenvalues & 4.29 & 2.70 & 1.60 & 1.01 & 1.00 \\
\hline Percentage of total variance & 33.79 & 20.12 & 12.38 & 6.49 & 5.89 \\
\hline Cumulative percentage & 33.79 & 53.92 & 66.29 & 72.79 & 78.69 \\
\hline
\end{tabular}

loading on DO, is denoted as organics component. PC2 explained $20.12 \%$, moderately with $\mathrm{TH}$ concentration due to mining water discharge. PC3 assigned as particulates pollution, correlated moderately with TDS and TSS, and explained $12.38 \%$ of total variance. PC4 accounted for $6.49 \%$ of total variance was contributed by T-coli concentration responsible for domestic discharge and PC5 accounted for $5.89 \%$ of total variance due to alkaline pH. Finally, a simplified index "WQI ${ }_{\text {pca }}$ " is developed as Eq. (12), which consists of arithmetic weighted mean, geometric mean and multiplied by three coefficients.

$\mathrm{WQI}_{\mathrm{pca}}=C_{\mathrm{pH}} C_{\mathrm{Tw}} C_{\mathrm{TH}}\left[\frac{1}{5} \sum_{i=1}^{5} P_{i} C_{i} * \frac{1}{2} \sum_{j=1}^{2} P_{j} C_{j} * \sum_{k=1}^{1} P_{k} C_{k}\right]^{1 / 3}$

where $\mathrm{WQI}_{\mathrm{pca}}$-is the water quality index based on results of PCA; $C_{i}$-is the value assigned to parameter $\mathrm{DO}, \mathrm{BOD}_{5}$, $\mathrm{COD}, \mathrm{SO}_{4}{ }^{2-}$, and $\mathrm{NO}_{3}{ }^{-}-\mathrm{N}$ after normalization; $P_{i}$-is the weight of the parameter $\mathrm{DO}, \mathrm{BOD}_{5}, \mathrm{COD}, \mathrm{SO}_{4}{ }^{2-}$, and $\mathrm{NO}_{3}{ }^{-}-\mathrm{N} ; C_{j}$-is the value assigned to parameters TDS and TSS after normalization; $P_{5}$-is the weight of the parameters TDS and TSS; $C_{k}$ - is the value assigned to parameter T-coli after normalization; $P_{k}$-is the weight of the parameter T-coli.

Three scaling coefficients are prefixed, which address the subindices of temperature $\left(C_{\mathrm{tem}}\right), \mathrm{pH},\left(C_{\mathrm{pH}}\right)$ and total hardness $\left(C_{\mathrm{TH}}\right)$, respectively. In addition, assigned weights to them are fewer in comparison with rest of the parameters, because lowered sensitivity of the overall index is inevitable, even having dramatic changes with different circumstances.

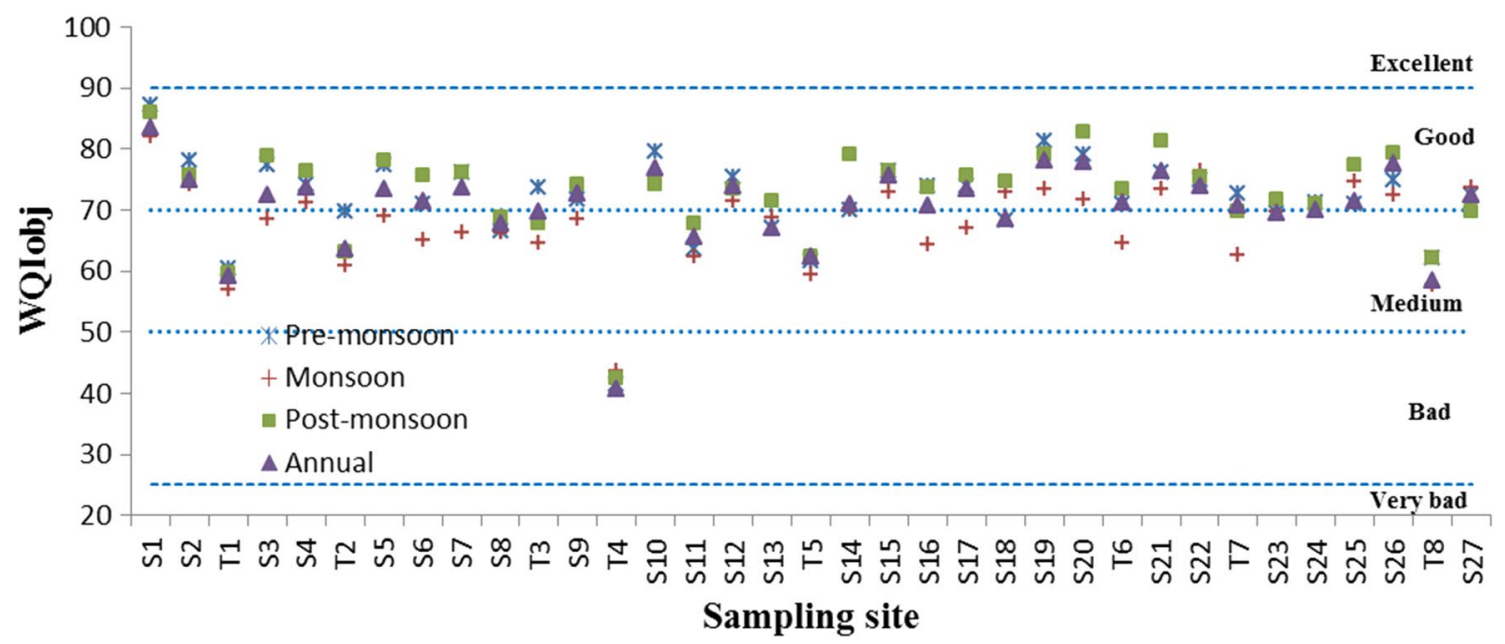

Fig. 4 Spatial and temporal variations of $\mathrm{WQI}_{\mathrm{obj}}$ at 35 sites in upper DRB 


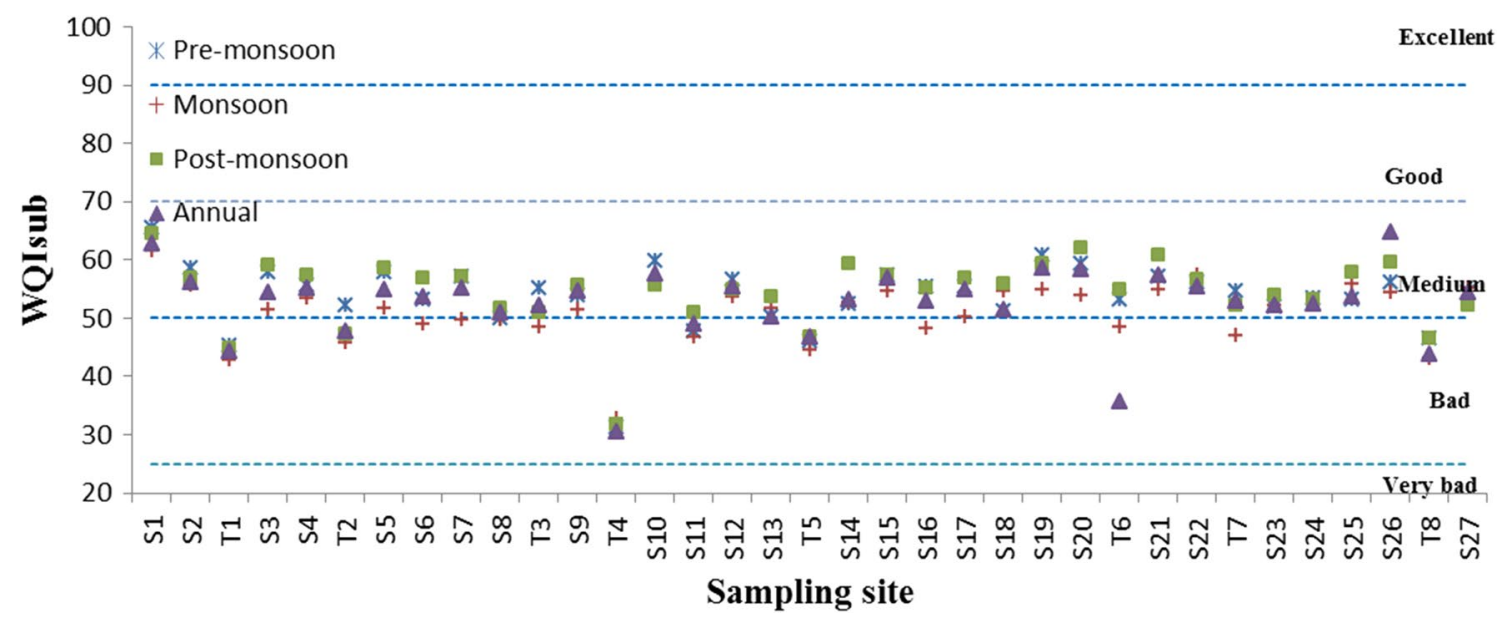

Fig. 5 Spatial and temporal variations of $\mathrm{WQI}_{\text {sub }}$ at 35 sites in upper DRB

\section{Evaluation of spatial and temporal variations of $W Q I_{\text {obj }}$ and $W Q I_{\text {sub }}$}

Both $\mathrm{WQI}_{\mathrm{obj}}$ and $\mathrm{WQI}_{\text {sub }}$ were computed at each sampling site and the results depicted in Figs. 4 and 5, respectively. $\mathrm{WQI}_{\mathrm{obj}}$ indicates good and medium water quality in most of the reaches in DRB throughout the year in comparison with the tributaries (Fig. 4). It may be due to high carrying or reaeration capacity of Damodar river (George et al. 2010; Verma et al. 2013), whereas WQI ${ }_{\text {sub }}$ tends to underestimate the water quality status due to the use of a subjective constant, which is not necessarily correlated with the measured parameters. Therefore, $\mathrm{WQI}_{\mathrm{obj}}$ could be considered as an appropriate indicator to assess spatiotemporal variations of surface water quality in DRB, as reported in earlier studies.

The computed $\mathrm{WQI}_{\mathrm{obj}}$ values were found in ranged from 41.52 to 87.27 (Avg. 71.72 \pm 7.64 ), 43.64 to 82.12 (Avg. $68.10 \pm 6.90$ ), and 42.42 to 86.06 (Avg. $72.69 \pm 7.80$ ) during pre-monsoon, monsoon, post-monsoon season, respectively, and overall annual ranged from 40.6 to 83.64, (Avg. $70.55 \pm 7.30$ ) which corresponded to good to medium category. While, mean annual $\mathrm{WQI}_{\mathrm{obj}}$ value for the tributaries was $61.97 \pm 9.35$ which lies in the medium category, except Garga nalla, a tributary which falls into the bad water quality category even for aquatic life. This could be because effluent of Bokaro thermal power plant as well as domestic sewage from Bokaro and Chas cities is discharged in the tributary.

Figure 4 also shows overall water quality is found better during post-monsoon season than during the monsoon season. During monsoon season, additional diffused pollution including percolation through land and soil cover and storm runoff generally bring pollutants into the river from overburdened dumps of opencast mines in the vicinity of mining area (Verma et al. 2012).
In the tributaries, annual mean value of $\mathrm{WQI}_{\mathrm{obj}}$ was $61.97 \pm 9.35$, which lies in the medium category. Although a stretch between downstream of Tenughat dam to Phusro along the main river, water quality lies in the good category as there are no major effluent discharges except some coal mines. In the middle region, a high concentration of COD, $\mathrm{BOD}_{5}$, TDS, TSS, $\mathrm{HCO}_{3}{ }^{-}$, and T-coli was observed due to industries and urban wastewater discharge and conform to the medium category. Although in lower region beyond Durgapur, observed water quality showed some improvement due to the river's assimilative capacity and absence of major industries and domestic effluent discharges.

In the context of temporal assessment, it was observed that water quality variation was not much distinct in seasons (Figs. 4, 5). Sampling sites S11, T1, T4, and T8 showed almost constant good water quality throughout study periods. The results also indicate that Garga nalla was the most polluted tributary with mean annual value of $42.04 \pm 1.12$, reflecting the bad category for human use/aquatic life when compared to other tributaries like Noonia nalla and Tamna nalla. These two tributaries flow through the major industrial areas and receive large quantities of industrial effluents besides domestic effluents; could be the reason

\section{Evaluation of spatial and temporal variations of $W_{\text {min }}, W_{D O}$, and $W Q I_{m}$}

In order to evaluate the feasibility of simplified developed indices: $\mathrm{WQI}_{\min }, \mathrm{WQI}_{\mathrm{DO}}$, and $\mathrm{WQI}_{\mathrm{m}}$ as indicators of the level of pollution, were determined at all 35 sampling sites. $\mathrm{WQI}_{\text {min }}, \mathrm{WQI}_{\mathrm{DO}}$, show approximately similar spatiotemporal trend as observed with the result of extended $W I_{o b j}$, based on 17 parameters (Figs. 6, 7). Recognizing the high 


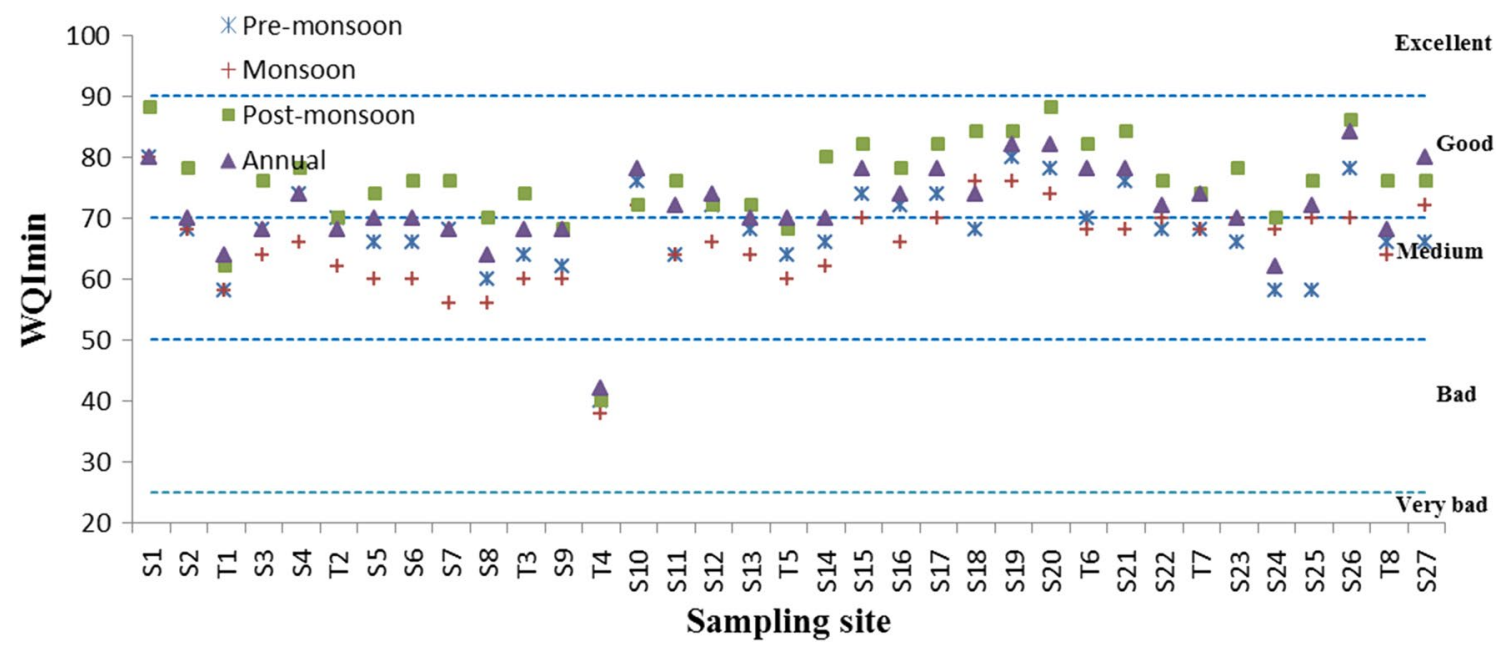

Fig. 6 Spatial and temporal variations of $\mathrm{WQI}_{\min }$ at 35 sites in upper DRB

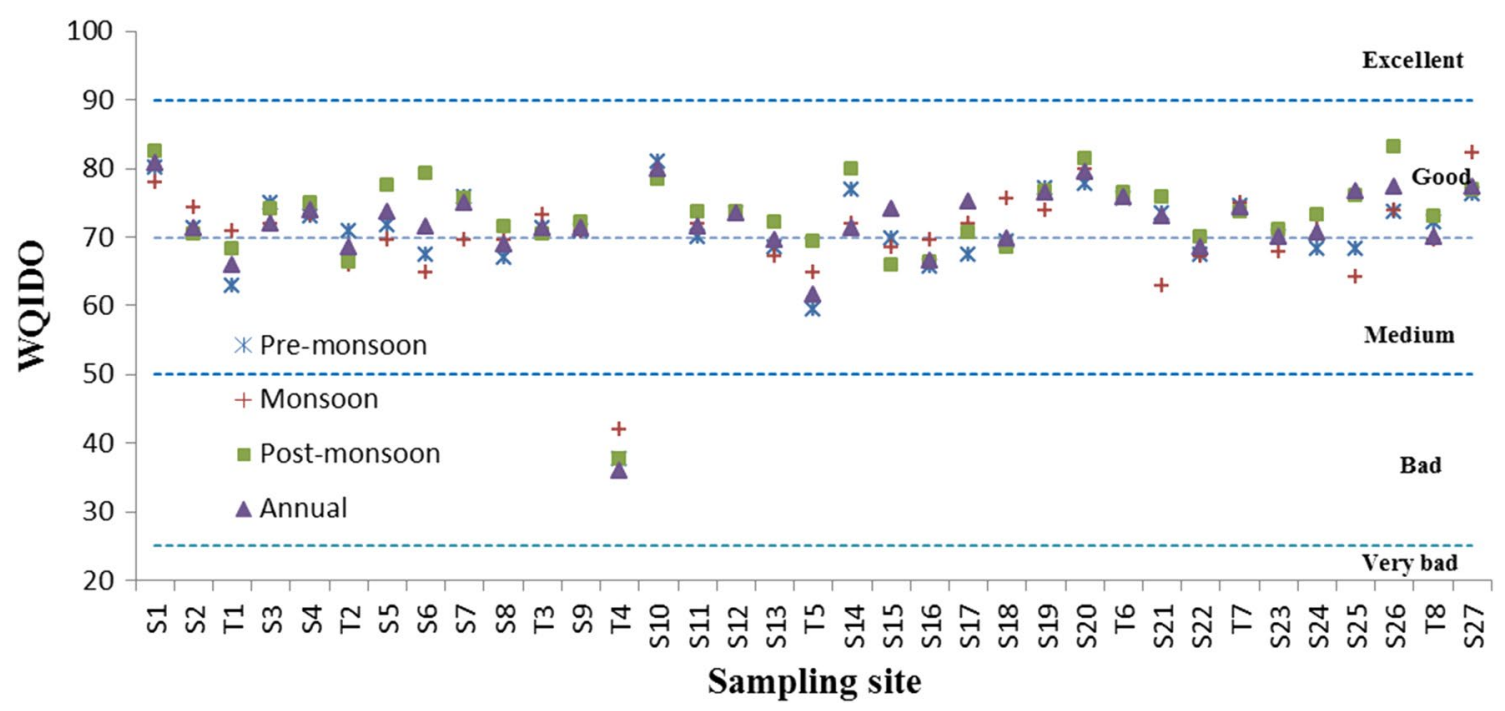

Fig. 7 Spatial and temporal variations of $\mathrm{WQI}_{\mathrm{DO}}$ at 35 sites in upper $\mathrm{DRB}$

relationship between $\mathrm{WQI}_{\mathrm{obj}}$ and $\mathrm{WQI}_{\text {min }}$, proposed $\mathrm{WQI}_{\mathrm{m}}$ shows almost similar trends as extended index "WQI $\mathrm{obj}$ " (Fig. 8).

\section{Evaluation of spatial and temporal variations of water quality using WQI $\mathrm{Ica}_{\text {pca }}$}

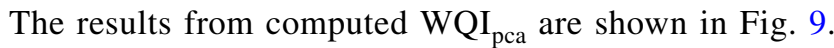
Numerically, the mean values of the seasonal and annual $\mathrm{WQI}_{\mathrm{pca}}$ calculations are slightly inferior to those obtained with the standard index $\mathrm{WQI}_{\mathrm{obj}}\left(r^{2}=.9\right.$; mean difference $=-5.0 ; P<.05)$.

\section{Comparison of developed indices with existing indices}

Both existing and developed indices were evaluated at each sampling site. However, computed values revealed that developed indices had identical trends of increasing or decreasing scores with slight variations over each sampling site.

Figure 10 shows quality criteria obtained by using different type of indices. It can be observed that results are in good agreement with $\mathrm{WQI}_{\min }$ and $\mathrm{WQI}_{\mathrm{DO}}$ with those from $\mathrm{WQI}_{\mathrm{obj}}$. However, $\mathrm{WQI}_{\mathrm{m}}$ is mostly agreed among them with $\mathrm{WQI}_{\mathrm{obj}}$. Thus, it is useful method for quick assessment of spatiotemporal variations in the river system, keeping in mind minimum cost involved. Furthermore, the variations 


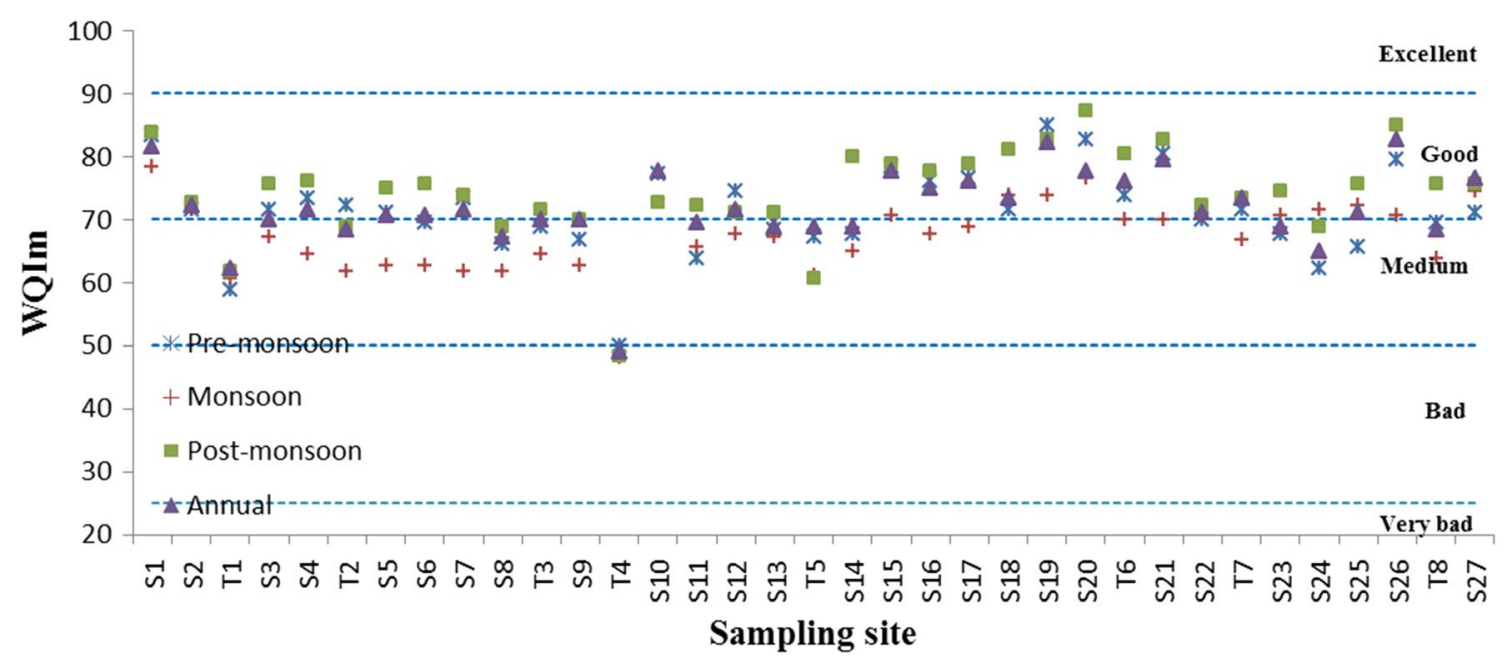

Fig. 8 Spatial and temporal variations of $\mathrm{WQI}_{\mathrm{m}}$ at 35 sites in upper DRB

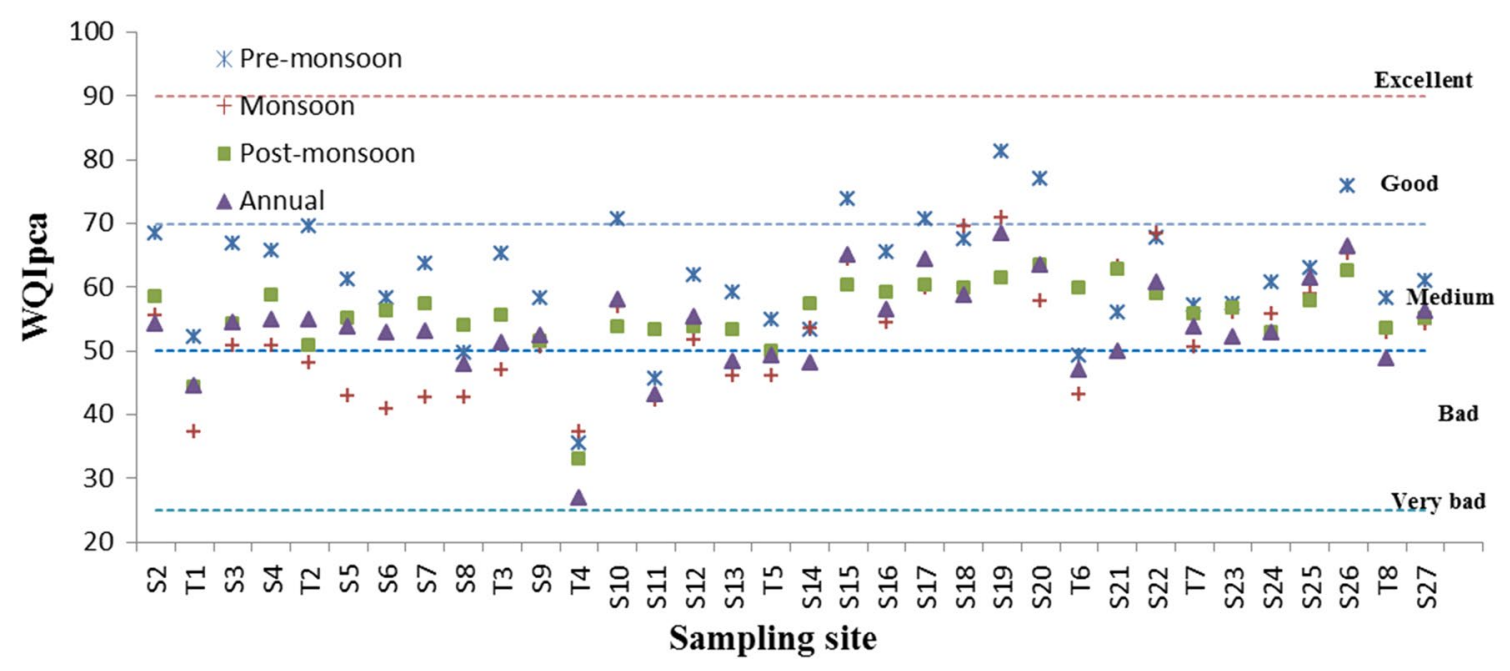

Fig. 9 Spatial and temporal variations of $\mathrm{WQI}_{\mathrm{pca}}$ at 35 sites in upper DRB

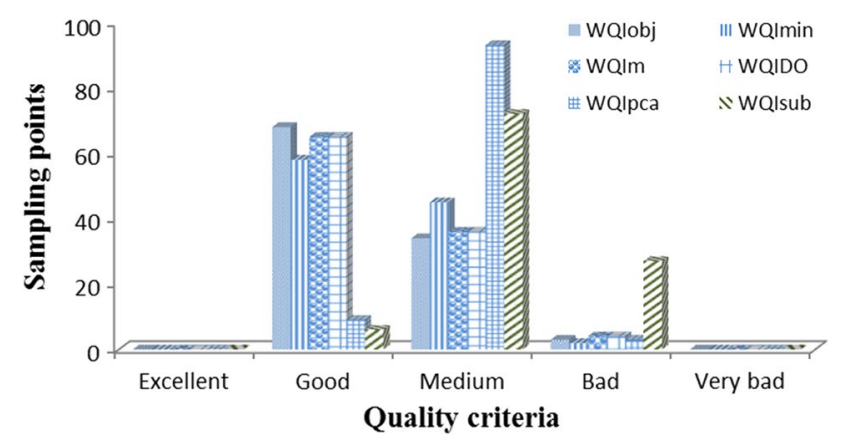

Fig. 10 Quality categorization of surface water samples in upper DRB among WQIs were also authenticated by ANOVA results. The outcome of ANOVA indicated that arithmetic WQI ${ }_{\text {obj }}$ exhibited a significant difference when compared with $\mathrm{WQI}_{\text {sub }}$ and $\mathrm{WQI}_{\mathrm{pca}}(P<.005)$ and had insignificant variations with $\mathrm{WQI}_{\mathrm{m}}, \mathrm{WQI}_{\text {min }}$, and $\mathrm{WQI}_{\mathrm{DO}}$ scores $(P=.433$ and $P=.883$, respectively). 


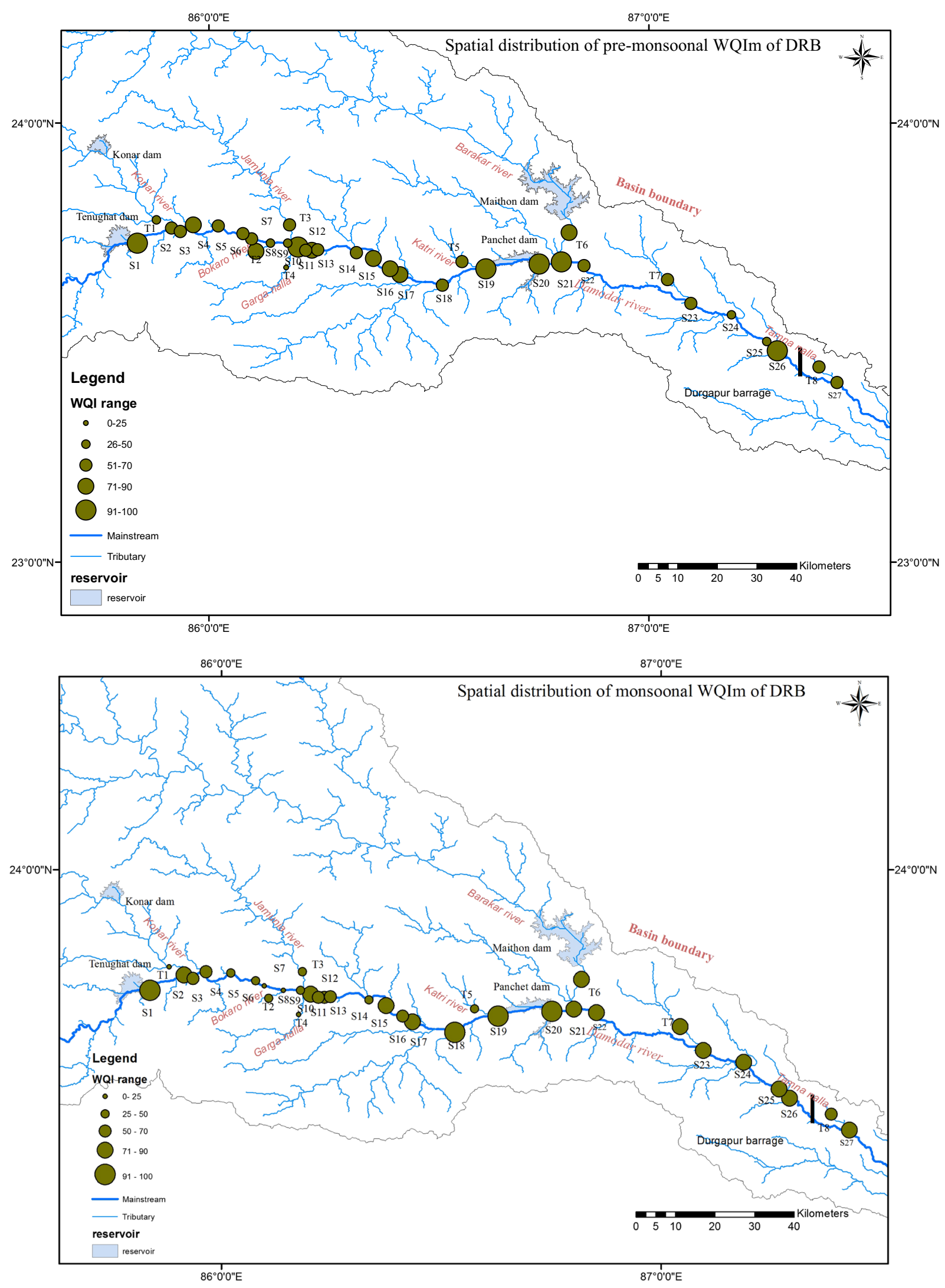

Fig. 11 Showing spatial and temporal distributions of $\mathrm{WQI}_{\mathrm{m}}$ in Damodar river and its tributaries and pollution level classification 


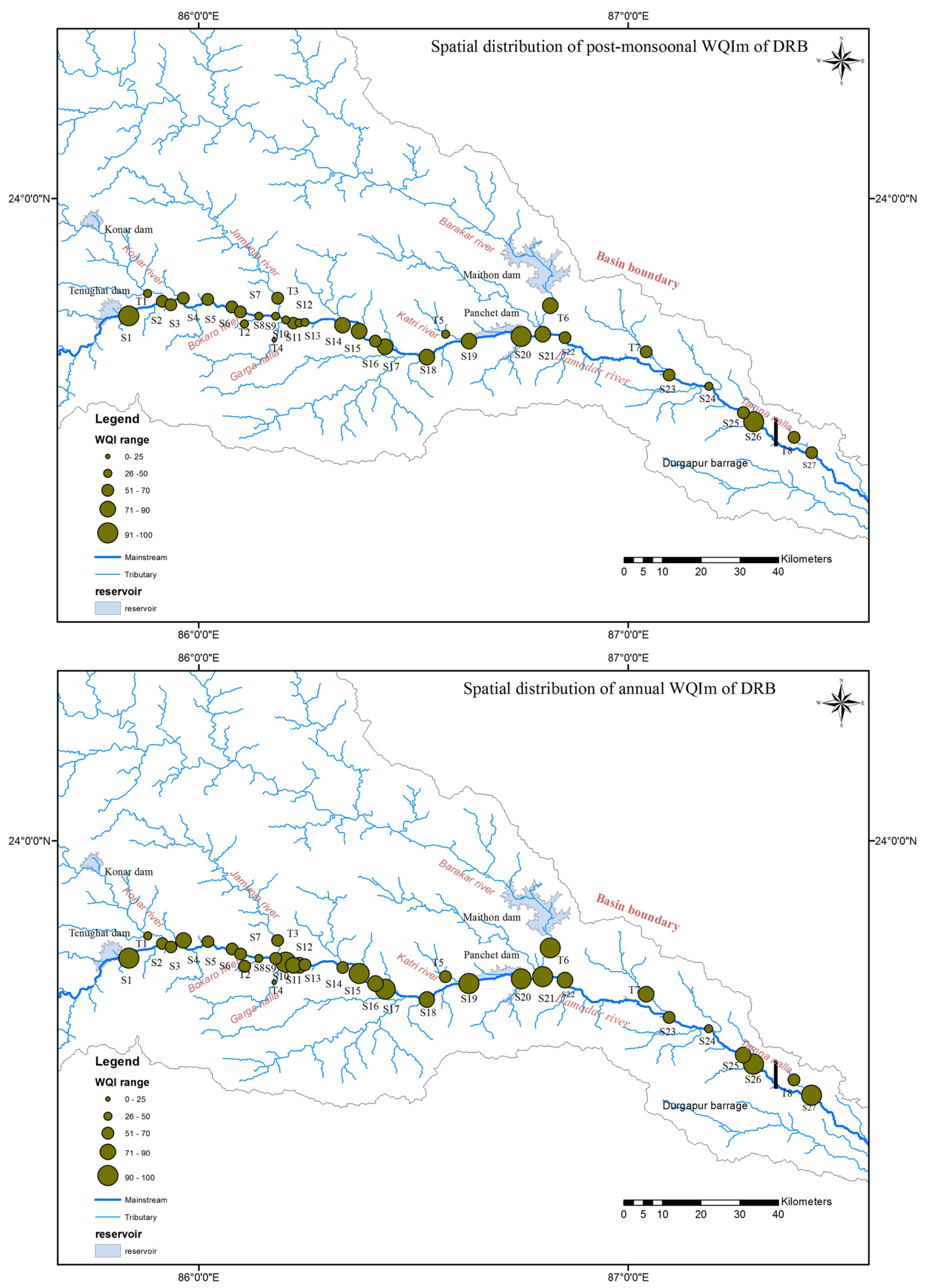

Fig. 11 (continued) 


\section{River classification}

As discussed in the previous section, $\mathrm{WQI}_{\mathrm{m}}$ is a most appropriate simplified index. Thus, based on the estimated values of $\mathrm{WQI}_{\mathrm{m}}$, river classification can be done for better management of the river Damodar and its catchment. The WQI $\mathrm{m}_{\mathrm{m}}$ data of various sampling sites have been pictorially represented using GIS and spatial interpolation method as shown in Fig. 11. These interpolations were run on pre-monsoon, monsoon, post-monsoon and annual WQI values and classified into five categories: very bad, bad, medium, good, and excellent. This classification can be directly used to stratify both sampling and management effort to more efficiently protect large river ecosystems

\section{Conclusions}

1. In this study, total 280 water samples were collected from 35 monitoring sites during 2007-2010 in DRB and 17 critical physicochemical-biological parameters were analyzed. Furthermore, spatiotemporal variations of surface water quality in the river system were also assessed by four ambiguity and eclipsing free simplified developed indices: $\mathrm{WQI}_{\mathrm{m}}, \mathrm{WQI}_{\mathrm{min}}, \mathrm{WQI}_{\mathrm{DO}}$, and $\mathrm{WQI}_{\mathrm{pca}}$ and two extended indices $\mathrm{WQI}_{\mathrm{obj}}$ and $\mathrm{WQI}_{\text {sub }}$.

2. A comparative analysis revealed that the simplified WQIs on an average represent similar result: class as well as spatiotemporal variations as obtained by an extended index "WQI ${ }_{\text {obj." However, }}$ WQI $_{m}$ is most agreed among them with $\mathrm{WQI}_{\mathrm{obj}}$. Therefore, developed indices could be useful in case of minimum parameters needed to assess water quality changes and river classification.

3. Average $\mathrm{WQI}_{\mathrm{m}}$ for years $2007-2010$ was calculated, and it was observed that out of 105 mean seasonal values, 64 and 35 lie in the good and the medium water quality category, respectively.

4. Results also revealed that the overall indices scores were found in the following order, post-monsoon $>$ premonsoon $>$ monsoon season, and this could be due to discharges from industries and domestic sources as well as low flow during that time of sampling. Overall, computed values of indices show that there was a slight improvement in water quality, which means the river water is not as much polluted for human use/aquatic life as it is usually projected in earlier studies.

5. The study also suggested simplified indices which could be used as simple tool to understand the status of the surface water quality especially for assessing suitability of human use/aquatic life in general and its comprehensive applications in spatial and temporal assessment could be applied to optimize future monitoring program by reducing the number of monitoring sites and parameters, and thus, the subsequent cost.

6. The developed indices clubbed with GIS can be directly used to analyze and compare condition across river basins and detect temporal variation. It could provide a technical support for governmental or local agencies to implement integrated river basin management.

Acknowledgements Authors are thankful to the Ministry of Water Resources (MOWR), Govt. of India, for the financial assistance extended to carry out this study. The authors would also acknowledge the assistance of colleagues at CIMFR, Barwa Road, Dhanbad, during data collection at various stages.

Open Access This article is distributed under the terms of the Creative Commons Attribution 4.0 International License (http://creativeco mmons.org/licenses/by/4.0/), which permits unrestricted use, distribution, and reproduction in any medium, provided you give appropriate credit to the original author(s) and the source, provide a link to the Creative Commons license, and indicate if changes were made.

\section{References}

Akkoyounlu A, Akiner ME (2012) Pollution evaluation in stream using water quality indices: a case study from Turkey's Sapanca lake basin. Ecol Ind 18:501-511

Almeida C, González S, Mallea M, González P (2012) A recreational water quality index using chemical, physical and microbiological parameters. Environ Sci Pollut Res 19(8):3400-3411

APHA, AWWA, WEF (2005) Standard methods for the examination of water and wastewater, 21st edn. American Public Health Association, Washington, DC

Ball RO, Church RL (1980) Water quality indexing and scoring. J Environ Eng Div ASCE 106:757-771

Bhargava D (1985) Expression for drinking water supply standards. J Environ Eng 111(3):304-316

Brown RM, McClelland NI, Deininger RA, Tozer RG (1970) A water quality index-Do we dare? Water Sew Works 117:339-343

Brown RM, McClelland NI, Deininger RA, Landwehr JM (1973) Validating the WQI. In: The paper presented at national meeting of American society of civil engineers on water resources engineering, Washington, DC

Cude CG (2001) Oregon water quality index: a tool for evaluating water quality management effectiveness. J Am Water Resour Assoc 37:125-137

Debels P, Figueroa R, Urrutia R, Barra R, Niell X (2005) Evaluation of water quality in the Chilla'n River (Central Chile) using physicochemical parameters and a modified water quality index. Environ Monit Assess 110:301-322

Dinius SH (1987) Design of an index of water quality. Water Resour Bull 23:833-843

Dojlido J, Raniszewski J, Woyciechowska J (1994) Water quality indexapplication for river in Vistula river basin in Poland. Water Sci Technol 30:57-64

European Union (EU) (1975) Council Directive 75/440/EEC of 16 June 1975 concerning the quality required of surface water intended for the abstraction of drinking water in the Member. Official Journal L/19425/07/1975, 0026-0031 
George J, Thakur SK, Tripathi RC, Ram LC, Gupta A, Prasad S (2010) Impact of coal industries on the quality of Damodar river water. Toxicol Environ Chem 92:1649-1664

Hanh PTM, Sthiannopkao S, Ba DT, Kim KW (2011) Development of water quality indexes to identify pollutants in Vietnam's surface water. J Environ Eng ASCE 137:273-283

Horton RK (1965) An index number system for rating water quality. J Water Pollut Control Fed 37(3):300-306

House MA, Ellis JB (1987) The development of water quality indices for operational management. Water Sci Technol 19:145-154

Jonnalagadda SB, Mhere G (2001) Water quality of the Odzi river in the eastern highlands of Zimbabwe. Water Res 35:2371-2376

Kannel PR, Lee S, Kanel SR, Khan SP, Lee Y (2007a) Spatial temporal variation and comparative assessment of water qualities of urban river system: a case study of the river Bagmati (Nepal). Environ Monit Assess 129:433-459

Kannel PR, Lee S, Lee YS, Kanel SR, Khan SP (2007b) Application of water quality indices and dissolved oxygen as indicators for river water classification and urban impact assessment. Environ Monit Assess 132:93-110

Koçer MAT, Sevgili H (2014) Parameters selection for water quality index in the assessment of the environmental impacts of landbased trout farms. Ecol Ind 36:672-681

Kumar D, Alappat BJ (2004) Selection of the appropriate aggregation function for calculating leachate pollution index. Pract Period Hazard Toxic Radioact Waste Manag 8(4):253-264

Liou SM, Lo SL, Wang HS (2004) A generalized water quality index for Taiwan. Environ Monit Assess 96:35-52

Ongley E (1998) Modernization of water quality programs in developing countries: issues of relevancy and cost efficiency. Water Qual Int $37-42$

Ott WR (1978) Environmental indices: theory and practice. Ann Arbor Science Publishers, Ann Arbor

Pesce SF, Wunderlin DA (2000) Use of water quality indices to verify the impact of Córdoba city (Argentina) on Suquía river. Water Res 34:2915-2926

Prasad B, Bose JM (2001) Evaluation of the heavy metal pollution index for surface and spring water near a lime stone mining area of the lower Himalayas. Environ Geol 41:183-188

Ross SL (1977) An index system for classifying river water quality. Water Pollut Control 76:113-122

Sarkar C, Abbasi SA (2006) Qualidex - a new software for generating water quality indices. Environ Monit Assess 119(1-3):201-231
Simoes FDS, Moreira AB, Bisinoti MC, Gimenez SMN, Yabe MJS (2008) Water quality index as a simple indicator of aquaculture effects on aquatic bodies. Ecol Ind 8:476-484

Singh RP, Nath S, Prasad SC, Nema AK (2008) Selection of suitable aggregation function for estimation of aggregate pollution index for river Ganges in India. J Environ Eng ASCE 134:689-701

Smith DG (1990) A better water quality indexing system for rivers and streams. Water Res 24:1237-1244

Štambuk-Giljanović N (1999) Water quality evaluation by index in Dalmatia. Water Res 33:3423-3440

Sutadian AD, Muttil N, Yilmaz AG, Perera BJC (2016) Development of river water quality indices - a review. Environ Monit Assess 188:58

Swamee PK, Tyagi A (2000) Describing water quality with aggregate index. J Environ Eng 126:451-455

Swamee PK, Tyagi A (2007) Improved method for aggregation of water quality subindices. J Environ Eng ASCE 133:220-225

Tiwary RK (1990) Studies on water pollution river due to coal mining and other industries activities in Dhanbad Jharia region. Unpublished Ph.D. thesis, Indian School of Mines, Dhanbad, Jharkhand

Tiwary RK (2004) Environmental impact of the oil spillage into Damodar river, India. In: Sinha IN, Ghose MK, Singh G (eds) Paper presented at the national seminar on environmental engineering with special emphasis on mining environment, NSEEME-2004, 19-20 March, pp 1-8

Verma S, Verma RK, Tiwary RK, Patel N, Murthy S (2012) Relationships between land-use/land-cover patterns and surface water quality in Damodar river basin, India. Glob J Appl Environ Sci 2:107-121

Verma RK, Murthy S, Tiwary RK, Verma S (2013) Evaluation of water quality index of Damodar river for drinking purpose using computer programming. Asian J Water Environ Pollut 10:27-40

Walski TM, Parker FL (1974) Consumers water quality index. J Environ Eng Div ASCE 100(3):593-611

Publisher's Note Springer Nature remains neutral with regard to jurisdictional claims in published maps and institutional affiliations. 